\title{
Formation of $\mathrm{Y}$-ketoaldehyde-protein adducts during ethanol- induced liver injury in mice
}

\author{
Sanjoy Roychowdhury ${ }^{*}$, Megan R. McMullen ${ }^{*}$, Michele T. Pritchard ${ }^{*}$, Wei Li\# ${ }^{\#}$, Robert G. \\ Salomon\#, and Laura E. Nagy $\S, \uparrow$ \\ "Department of Pathobiology Case Western Reserve University, Cleveland, Ohio \\ $\S$ Department of Gastroenterology, Cleveland Clinic Case Western Reserve University, Cleveland, \\ Ohio \\ †Department of Nutrition Case Western Reserve University, Cleveland, Ohio \\ \#Department of Chemistry Case Western Reserve University, Cleveland, Ohio
}

\begin{abstract}
Ethanol metabolism promotes formation of a variety of reactive aldehydes in the liver. These aldehydes can rapidly form covalent protein adducts. Accumulating evidence indicates that these protein adducts may contribute to ethanol-mediated liver injury. Overproduction of $\gamma$-ketoaldehydes, levuglandins (LGs) and isolevuglandins (isoLGs), is implicated in the pathogenesis of several chronic inflammatory diseases. $\gamma$-ketoaldehydes can form protein adducts orders of magnitude more quickly than 4-hydroxynonenal (4-HNE) or malondialdehyde. We hypothesized that ethanol-induced oxidative stress in vivo results in overproduction of $\mathrm{LGE}_{2}$ - and iso[4] $\mathrm{LGE}_{2}$-protein adducts in mouse liver. Female C57BL/6 mice were allowed free access to an ethanol containing diet for up to 39 days or pair-fed control diets. Pathological markers of ethanol-induced hepatic injury including serum alanine aminotransferase, hepatic triglyceride and CYP2E1 were elevated in response to ethanol feeding. Ethanol-induced formation of iso[4] $\mathrm{LGE}_{2}, \mathrm{LGE}_{2}$ and 4-HNE-protein adducts in mouse liver was dependent on both dose and duration of ethanol feeding. Deficiency of cyclooxygenase 1 or 2 did not prevent ethanol-induced iso[4] $\mathrm{LGE}_{2}$ or $\mathrm{LGE}_{2}$ adducts in the liver, but adduct formation was reduced in both TNFR1 and CYP2E1 deficient mice. In summary, ethanol feeding enhanced $\gamma$ ketoaldehyde-protein adducts production via a TNFR1/CYP2E1-dependent, but cyclooxygenaseindependent, mechanism in mouse liver.
\end{abstract}

\section{Keywords}

Levuglandin $\mathrm{E}_{2}$; iso[4]levuglandin $\mathrm{E}_{2}$; 4-hydroxynonenal; tumor necrosis factor $\alpha$; alcoholic liver disease

\footnotetext{
(c) 2009 Elsevier Inc. All rights reserved.

Address correspondence to: Sanjoy Roychowdhury Cleveland Clinic Lerner Research Institute/NE40 9500 Euclid Ave Cleveland OH 44195 Phone: 216-444-4201 Fax: 216-636-1493 roychos@ccf.org.

Publisher's Disclaimer: This is a PDF file of an unedited manuscript that has been accepted for publication. As a service to our customers we are providing this early version of the manuscript. The manuscript will undergo copyediting, typesetting, and review of the resulting proof before it is published in its final citable form. Please note that during the production process errors may be discovered which could affect the content, and all legal disclaimers that apply to the journal pertain.
} 


\section{Introduction}

Increasing evidence indicates that reactive oxygen species (ROS) play a critical role in ethanolinduced liver injury [1,2]. Ethanol-induced oxidative damage causes lipid peroxidation resulting in the formation of a variety of reactive molecules, including malondialdehyde (MDA) and 4-hydroxynonenal (4-HNE) [3]. These reactive aldehydes can readily bind to a variety of cellular proteins and in so doing impair their function or act as neo-antigens eliciting deleterious immune responses [4]. ROS can also induce cyclo-oxygenation of polyunsaturated fatty acids, including arachidonic acid, leading to the formation of various $\gamma$-ketoaldehydes [5-7]. Such ketoaldehydes react with proteins much faster than MDA or 4-HNE, generating covalent protein adducts.

In addition to the ROS-dependent formation, $\gamma$-ketoaldehydes can also be formed via the rearrangement of prostaglandin endoperoxides produced by the enzymatic activity of cyclooxygenases (COX). Formation of $\gamma$-ketoaldehydes due to nonenzymatic rearrangement of prostaglandin endoperoxide intermediates can represent about $20 \%$ of total COX-reaction products under normal physiological conditions [8]. COX plays a critical role in a variety of hepatic pathological conditions, including ethanol-induced liver damage $[9,10]$. However, the mechanism of COX-mediated tissue injury during ethanol feeding is still not understood.

Among various $\gamma$-ketoaldehydes, levuglandins (LGs) (e.g., $\mathrm{LGE}_{2}$ ) and isolevuglandins (isoLGs) (e.g., iso[4] $\mathrm{LGE}_{2}$ ) have been reported to accumulate in various pathophysiological conditions $[6,11,12]$. Both $\mathrm{LGE}_{2}$ and iso[4] $\mathrm{LGE}_{2}$-protein adducts are elevated in blood plasma from coronary artery bypass patients with atherosclerosis (AS) and from end-stage renal disease patients compared to healthy volunteers [6]. In addition, protein adducts of iso[4] $\mathrm{LGE}_{2}$ increase several fold in plasma in a Candida sepsis-induced model of inflammation [13]. $\mathrm{LGE}_{2}$-protein adducts are also elevated in the hippocampus of Alzheimer's disease patients compared with their age-matched controls. Moreover, there is a strong correlation between the levels of iso[4] $\mathrm{LGE}_{2}$-adducts and the severity of Alzheimer's disease progression [12]. While studies have shown that $\mathrm{LGE}_{2}$ and iso[4] $\mathrm{LGE}_{2}$-protein adducts accumulate during inflammatory conditions, the differential contribution of COX and ROS-mediated pathways to the formation of $\gamma$-ketoaldehyde-protein adducts in vivo is not known.

Ethanol-induced oxidative stress is likely a result of multiple pathways, such as increased cytokine expression and/or CYP2E1 expression. TNF- $\alpha$ plays a central role in alcohol-induced oxidative stress and liver injury [14]. Several reports indicate that elevated levels of circulating endotoxins, increased production of hepatic TNF- $\alpha$ and ROS work in concert to promote ethanol-induced liver injury. TNF- $\alpha$ can induce mitochondrial ROS production in hepatocytes [15]. Animals deficient in TNF- $\alpha$ receptor 1 (TNFR1) [16] or treated with TNF- $\alpha$ neutralizing antibody are protected from ethanol-induced lipid peroxidation and liver injury [17]. Since TNFR1 deficiency offers protection against ethanol-induced liver injury and oxidative stress, we reasoned that this model can be a useful tool to assess the contribution of ethanol-induced ROS towards formation of $\gamma$-ketoaldehydes in response to ethanol feeding. Induction of hepatic CYP2E1 also contributes to ethanol-induced ROS generation and the deficiency of CYP2E1 offers protection to ethanol-induced oxidative stress and steatosis [18]. To assess the direct contribution of CYP2E1 to ethanol-induced $\gamma$-ketoaldehyde generation, we also studied the formation of $\gamma$-ketoaldehydes in response to ethanol feeding in the liver of CYP2E1-deficient mice.

Here we detect, for the first time, the formation of specific $\gamma$-ketoaldehydes, $\mathrm{LGE}_{2}$ and iso[4] $\mathrm{LGE}_{2}$-protein adducts in mouse liver in response to ethanol feeding. Making use of COX-1, COX-2, TNFR1 and CYP2E1 knock out mice, we assessed the contribution of ROS and COX towards ethanol-induced $\gamma$-ketoaldehyde formation in the liver. Our results demonstrated that 
the formation of $\mathrm{LGE}_{2}$, iso[4] $\mathrm{LGE}_{2}$ and 4-HNE-protein adducts in mouse liver in response to ethanol feeding is independent of COX-1 or 2, but is TNFR1 and/or CYP2E1-dependent.

\section{Materials and Methods}

\section{Materials}

Female C57BL/6 mice (8-10 weeks old) were purchased from Jackson Laboratories (Bar Harbor, Maine). Lieber-DeCarli high-fat ethanol and control diets were purchased from Dyets (Bethlehem, PA). Female COX $-1^{-l-}$ and $\mathrm{COX}-1^{+/+}$mice $\left(\mathrm{B} 6 ; 129 \mathrm{P} 2 \mathrm{Ptgs} 1^{\mathrm{tm} 1 \mathrm{Unc}}\right)$ as well as COX $-2^{-/-}$and COX $-2^{+/+}$mice (B6; 129P2Ptgs $2^{\mathrm{tm} 1 \mathrm{Sm} 1}$ ) were purchased from Taconic Farms

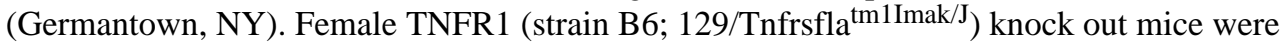
purchased from The Jackson Laboratory (Bar Harbor, ME). CYP2E1 $1^{-1-}$ mice, on a $129 / \mathrm{Sv}-$ C57BL/6N mixed background (generated by Dr. Frank J. Gonzalez, Laboratory of Metabolism, National Institute of Health, Bethesda, MD [19,20]) were a generous gift from Dr. Arthur Cederbaum (New York). Antibodies were from the following sources: CYP2E1 (Research Diagnostics, Inc., Flanders, NJ), 4-HNE-antiserum (Alpha Diagnostics, San Antonio, TX) and TNF- $\alpha$ Minneapolis, MN). Anti-iso[4] $\mathrm{LGE}_{2}$ and $\mathrm{LGE}_{2}$ antibodies have been previously characterized by Salomon et al. [21]. Alexa fluor- 488 conjugated secondary antibodies were purchased from Invitrogen (Carlsbad, CA).

\section{Ethanol feeding}

All procedures using animals were approved by the Cleveland Clinic Institutional Animal Care and Use Committee. Mice were housed in shoe-box cages ( 2 animals / cage) with microisolator lids. Standard microisolator handling procedures were used throughout the study. Mice were randomized into ethanol-fed and pair-fed groups and then adapted to control liquid diet for 2 days. The ethanol-fed group was allowed free access to an ethanol containing diet with increasing concentrations of ethanol: $1 \%$ (vol / vol) and 2\% each for 2 days, then $4 \%$ ethanol for 7 days, and finally $5 \%$ ethanol for a further 4 weeks. In the experiment using CYP2E1deficient mice, diets were increased to $6 \%$ ethanol for $1 \mathrm{wk}$ after $5 \%$ for $1 \mathrm{wk}$. The $5 \%$ (vol / vol) diet provided ethanol as 26.9 percent of total calories in the diet. For the dose-response experiment, a short-term ethanol feeding paradigm was used, in which mice were allowed free access to $1 \%$ ( $\mathrm{vol} / \mathrm{vol}$ ) ethanol for 2 days and then $2 \%, 4 \%$ or $6 \%$ ethanol for a further 2 days. This short-term protocol of ethanol feeding is designed to model the binge drinking behavior of humans. Control mice were pair-fed diets which iso-calorically substituted maltose dextrins for ethanol over the entire feeding period. At the end of each experiment, mice were anesthetized, blood samples taken into non-heparinized syringes from the posterior vena cava, livers blanched with saline via the hepatic portal vein and then excised. Portions of each liver were then either fixed in formalin or frozen in optimal cutting temperature (OCT) compound (Sakura Finetek U.S.A., Inc., Torrance CA) for histology, frozen in RNAlater (Qiagen, Valencia, CA) or flash frozen in liquid nitrogen and stored at $-80{ }^{\circ} \mathrm{C}$ until further analysis. Blood was transferred to EDTA-containing tubes for the isolation of plasma. Plasma was then stored at $-80{ }^{\circ} \mathrm{C}$.

\section{Plasma ALT measurement}

Plasma samples were assayed for alanine aminotransferase (ALT) using a commercially available enzymatic assay kit (Diagnostic Chemicals, LTD, Oxford, CT) following the manufacturer's instructions.

\section{Liver histology and triglycerides}

Formalin-fixed tissues were paraffin-embedded, sectioned and stained with hematoxylin and eosin. Sections were coded prior to analysis and examined by two independent individuals. 
For Oil Red O staining, 10 micron liver sections were cut from frozen OCT-embedded samples and affixed to a microscope slide. Slides were stored at $4{ }^{\circ} \mathrm{C}$ until staining. Liver sections were air dried for 5-10 min at room temperature and stained in fresh Oil Red O (Sigma, St. Louis, MO) for $12 \mathrm{~min}$, rinsed in water and counterstained with hematoxylin. Total liver triglycerides were measured using the Triglyceride Reagent Kit from Pointe Scientific Inc. (Lincoln Park, Michigan).

\section{Immunohistochemistry}

Formalin-fixed paraffin-embedded liver sections were de-paraffinized in Safeclear II xylene substitute (Protocol, Kalamazoo, MI), (3 times 3 min each) and hydrated consecutively in 100\% (2 times, 1 min each), 70\% and 30\% ethanol followed by two washes in PBS (2 times, 5 min each). Sections were blocked with PBS containing 2\% BSA and 0.1\% Triton-X-100 for $1 \mathrm{~h}$ and incubated overnight with polyclonal rabbit anti 4-HNE antibody or iso[4]LGE 2 or $\mathrm{LGE}_{2}$ anti-sera (diluted 1:250 in blocking buffer) at $4{ }^{\circ} \mathrm{C}$ in a humidified chamber. After three washes in PBS ( 3 times 5 min each), sections were incubated with the fluorochrome-conjugated secondary antibody (Alexa fluor 488 labeled goat-anti-rabbit IgG, 1:250 diluted in blocking buffer) for $2 \mathrm{~h}$ at room temperature. Sections were then washed three times in PBS and mounted with VECTASHIELD containing anti-fade reagent (Vector Laboratories, Inc., Burlingame, CA). Fluorescence images were acquired using a LEICA confocal microscope. No specific immunostaining was seen in sections incubated with PBS rather than the primary antibody. Images were semi-quantified using ImagePro Plus software (Media Cybernetics, Inc, Bethesda, MD).

\section{Liver homogenization}

$0.5-1.0 \mathrm{~g}$ of frozen liver tissue was homogenized in $10 \mathrm{ml} / \mathrm{g}$ tissue in lysis buffer $(50 \mathrm{mM}$ Tris$\mathrm{HCl}, \mathrm{pH} 7.4,1 \% \mathrm{NP}-40,0.25 \%$ Na-deoxycholate, $150 \mathrm{mM} \mathrm{NaCl}, 1 \mathrm{mM}$ EDTA with added protease inhibitors Complete TM (Roche Diagnostics, Mannheim, Germany), $17.5 \mu \mathrm{g} / \mathrm{ml}$ aprotinin, $5 \mu \mathrm{g} / \mathrm{ml}$ bestatin, $10 \mu \mathrm{g} / \mathrm{ml}$ leupeptin, $1 \mathrm{mg} / \mathrm{ml}$ bacitracin, and $20 \mu \mathrm{g} / \mathrm{ml} \mathrm{E64)} \mathrm{and}$ phosphatase inhibitors (1 $\mathrm{mM}$ vanadate and $10 \mathrm{mM}$ Na pyrophosphate)) using 15 strokes in a glass on glass homogenizer (loose pestle). After $15 \mathrm{~min}$ on ice, samples were centrifuged at $16,000 \times \mathrm{g}$ for $15 \mathrm{~min}$ to remove insoluble material. Protein concentrations were measured by BCA (bicinchoninic acid) protein assay (Pierce, USA). Samples were used to measure hepatic cytokine concentrations (see below) or normalized and prepared in Laemmli buffer and boiled for $5 \mathrm{~min}$. Samples were separated by SDS-polyacrylamide gel electrophoresis and transferred to membranes for Western blotting. Membranes were probed with specific antibodies against CYP2E1 overnight at $4{ }^{\circ} \mathrm{C}$, then washed and incubated for $1 \mathrm{~h}$ in an appropriate secondary antibody coupled to horseradish peroxidase. Bound antibody was detected by chemiluminescence. Immunoreactive protein quantity was assessed by scanning densitometry using Image-Pro Plus software (Media Cybernetics, Inc, Bethesda, MD).

\section{ELISA for iso[4] $\mathrm{LGE}_{2}$}

ELISA for iso[4] $\mathrm{LGE}_{2}$ was carried out as detailed by Salomon et al [6]. Briefly, liver homogenates were prepared as described except that $50 \mu \mathrm{M}$ butylated hydroxytoluene (BHT) and $100 \mu \mathrm{M}$ diethylenetriamine pentaacetic acid (DTPA) were added to the buffer to prevent aerial oxidation of lipids during homogenization. $50 \mu \mathrm{g}$ of protein was used in the ELISA.

\section{Statistical analysis}

Values reported are means + SEM. Because of the logistics of animal care, several feeding trials were carried out and combined for the final data analysis. Data were analyzed by general linear models procedure (SAS, Carey, IN). Data were log transformed if needed to obtain a normal distribution. Follow-up comparisons were made by least square means testing. 


\section{Results}

Here we have utilized both long-term (chronic) and short-term (binge) models of ethanol exposure. In a chronic model, mice were allowed free access to increasing concentrations of ethanol for 39 days. There was a gradual accumulation of neutral lipids in the liver during this period ranging from mostly microvesicular lipid droplets at 7 days $(4 \% \mathrm{~d} 3)$ to the predominantly macrovesicular droplets by 39 days (5\% wk 4, Figure 1A). This pattern of neutral lipid accumulation is supported by quantitative measurements of hepatic triglyceride previously assayed in these mice [22]. Plasma ALT, a measure of hepatocyte injury, also increases with a similar pattern during ethanol exposure in these mice [22].

In the short-term model of ethanol exposure, mice were allowed access to a $1 \%$ ethanol diet for 2 days followed by either a 2, 4 or $6 \%$ ethanol containing diet for 2 additional days. Hepatic triglycerides, assessed by Oil Red O staining, increased at the higher doses (4 and 6\%) of ethanol (Figure 1B). Quantitative measurements of hepatic triglycerides, as well as plasma ALT, also increased at 4 and $6 \%$ ethanol (Figure 2). CYP2E1, one of the important ethanol metabolizing enzymes in the liver, plays a critical role in ethanol-induced hepatic injury [18, 23]. Hepatic CYP2E1 protein content increased after chronic ethanol feeding starting as early as 11 days ( $4 \% \mathrm{~d} 7)$ and remained elevated for the remainder of the feeding protocol (Figure $3 \mathrm{~A})$. In the short-term model of ethanol exposure (4d), CYP2E1 content was increased only at the 6\% ethanol feeding (Figure 3B).

After chronic ethanol exposure for 39 days (5\% wk 4), protein adducts of different lipid peroxidation products, including 4-HNE, $\mathrm{LGE}_{2}$ and iso[4] $\mathrm{LGE}_{2}$, were detected in the liver using immunohistochemistry (Figure 4A). Protein adducts of iso[4] $\mathrm{LGE}_{2}$ were also quantified by ELISA. Iso[4] $\mathrm{LGE}_{2}$-protein adducts were 1.8 fold higher in livers from chronic ethanolfed mice (39d, 5\% wk 4) compared to pair-fed controls (Figure 4B). During the course of chronic ethanol feeding, increases in 4-HNE, $\mathrm{LGE}_{2}$ and iso[4] $\mathrm{LGE}_{2}$-adducts were elevated significantly as early as 7 days ( $4 \% \mathrm{~d} 3$, Figure 5), concurrent with the increase in plasma ALT and hepatic TG [22]. In the short-term model of ethanol exposure (4d), 4-HNE, LGE $_{2}$ and iso [4] $\mathrm{LGE}_{2}$-protein adducts were increased only at $6 \%$ ethanol feeding (Figure 6), where the increase in plasma ALT and hepatic TG were highest (Figure 2). While some of the liver sections examined had comparatively higher accumulation of ethanol-induced 4-HNE, $\mathrm{LGE}_{2}$ and iso[4]LGE 2 -protein adducts around the central veins, in the majority of the sections, no zone-specific adduct accumulation was detected.

We next investigated the mechanism of ethanol-induced $\mathrm{LGE}_{2}$ and iso[4] $\mathrm{LGE}_{2}$-adduct formation by immunohistochemistry using genetically modified mice. If formation of $\mathrm{LGE}_{2}$ and iso[4] $\mathrm{LGE}_{2}$ were dependent on cyclooxygenase activity, adduct formation would be reduced in the liver of COX-1 or COX-2-deficient mice in response to ethanol feeding. Ethanol feeding for 7 days increased $\mathrm{LGE}_{2}$ and iso[4] $\mathrm{LGE}_{2}$-protein adducts in both wild type and COX-1 or 2 deficient mouse livers (Figure 7 and 8). These data exclude a role for both cyclooxygenase isozymes, COX-1 and COX-2, in ethanol-mediated $\mathrm{LGE}_{2}$ and iso[4] $\mathrm{LGE}_{2}$ protein adduct formation.

Upregulation of pro-inflammatory cytokines, including TNF- $\alpha$, is a key event during ethanolinduced liver injury. Ethanol feeding results in a biphasic induction of TNF- $\alpha$ in mouse liver with an early transient peak at 4 days $(2 \% \mathrm{~d} 2)$, followed by a later increase at 39 days $(5 \% \mathrm{wk}$ 4) [22]. Previous reports indicate that ethanol-induced TNF- $\alpha$ expression can trigger ROS overproduction [24]. We therefore hypothesized that deficiency of TNFR1 would restrict the formation of hepatic ROS and in turn, prevent the accumulation of 4-HNE and iso[4] $\mathrm{LGE}_{2}$ protein adducts in response to ethanol feeding. In agreement with our hypothesis, formation 
of ethanol-induced 4-HNE and iso[4] $\mathrm{LGE}_{2}$-protein adducts were blunted in TNFR1-knockout mouse livers compared to their wild type counterparts at day 11 (4\% d7) (Figure 9).

Since ethanol metabolism via CYP2E1 also generates ROS, deficiency of CYP2E1 would also be expected to prevent ROS-mediated 4-HNE and iso[4] $\mathrm{LGE}_{2}$-protein adducts formation following ethanol exposure. Ethanol-induced 4-HNE and iso[4] $\mathrm{LGE}_{2}$-protein adducts were prevented in CYP2E1 deficient mice compared to the wild type counterparts (Figure 10), suggesting a second mechanism of ethanol-induced ROS generation resulting in the formation of 4-HNE and iso[4] $\mathrm{LGE}_{2}$-protein adducts following ethanol exposure.

\section{Discussion}

Oxidative stress and lipid peroxidation play critical roles in ethanol-induced liver injury [1].

ROS generated in the liver in response to ethanol exposure can oxidize a plethora of different tissue macromolecules, including lipids, generating reactive aldehydes. These reactive aldehydes bind to cellular proteins generating stable covalent adducts [25]. Aldehyde-protein adducts, including 4-HNE and MDA, are detectable in patients with alcoholic liver disease [26]. Recently, a new family of reactive aldehydes, that includes $\mathrm{LGE}_{2}$ and iso[4] $\mathrm{LGE}_{2}$, generated from arachidonic acid, was reported to accumulate in various oxidative stress related diseases $[6,8,13] . \mathrm{LGE}_{2}$ and iso[4] $\mathrm{LGE}_{2}$ can bind to proteins much faster than 4-HNE and MDA. A direct in vitro comparison of the protein binding capacity of $\mathrm{LGE}_{2}$ and 4-HNE demonstrates that $\mathrm{LGE}_{2}$ binds to BSA within seconds as compared to 4-HNE, which requires 10 minutes to bind to the same amount of protein [27]. Moreover, levuglandins target lysyl amino groups of proteins while 4-HNE has a higher affinity towards cysteine [7]. Here we assessed whether ethanol exposure increases the production of novel $\gamma$-ketoaldehydes, $\mathrm{LGE}_{2}$ and iso[4] $\mathrm{LGE}_{2}$, in addition to the lipid peroxidation marker 4-HNE, in mouse liver. Both chronic (39d) and short-term (4d) ethanol feeding induced the accumulation of protein adducts of reactive $\gamma$-ketoaldehydes, $\mathrm{LGE}_{2}$ and iso[4] $\mathrm{LGE}_{2}$, as well as the hydroxyalkenal, 4-HNE, in mouse liver. Formation of these lipid peroxidation products was dependent on duration and dose of ethanol exposure. Adducts accumulated at the same time as other markers of liver injury were detected, including plasma ALT and hepatic TG, but subsequent to an early spike in the inflammatory cytokine, TNF- $\alpha$. Moreover, formation of these adducts was dependent on TNF- $\alpha$ signaling via TNFR1 (Figure 9), but independent of the arachidonic acid metabolizing enzymes, cyclooxygenase 1 and 2 (Figure 10).

The formation of 4-HNE or MDA-protein adducts is associated with the development of a number of oxidative stress-related diseases, including alcoholic liver injury [28]. Formation of $\gamma$-ketoaldehydes, including $\mathrm{LGE}_{2}$ and iso[4] $\mathrm{LGE}_{2}$, is implicated in a variety of oxidative stressrelated pathological conditions. $\mathrm{LGE}_{2}$ and their stereo isomers (isoLGE 2 ), as well as structural isomers, including iso[4] $\mathrm{LGE}_{2}$, exhibit extremely high reactivity toward proteins. They covalently bind to proteins within seconds [29], and their protein adducts are resistant to proteolytic degradation [30,31]. Therefore, in contrast with other products of lipid oxidation, e.g., 4-HNE, MDA or isoprostanes, that are rapidly cleared, LG/isoLG-protein adducts accumulate in vivo [13]. Consequently, their levels provide a dosimeter-like cumulative index of oxidative stress. Disease-related elevations of LG/isoLG-protein adducts are found in the plasma from patients with cardiovascular disease or end-stage renal disease [6,8], in mouse plasma from a Candida-induced sepsis model of chronic inflammation [13], in the plaques of Alzheimer's disease patients [32] and in the epicardial border zone and myocardium below the epicardium in the healing canine infracted heart [33,34]. LG/isoLGs inhibit the activities of cellular proteins, including proteases such as calpain-1 [31,35] and the proteasome $[30,31]$, as well as tubulin [36], and ion channels [5,33]. The irreversible, covalent modification of myocardial ion channel proteins may contribute to ischemia-related conduction abnormalities and arrhythmias. As little as one molecule of $\mathrm{LGE}_{2}$ per monomer of tubulin is sufficient to 
inhibit its polymerization to form microtubules, and similar levels of $\mathrm{LGE}_{2}$ inhibit the mitosis of sea urchin eggs [36]. Elevated levels of iso[4] $\mathrm{LGE}_{2}$-modified proteins are found in the trabecular meshwork (TM) tissue from the eyes of glaucoma patients [35]. Massive quantities of iso[4] $\mathrm{LGE}_{2}$-modified calpain-1, that is inactive, accumulate in the TM of individuals with primary open angle glaucoma. This may contribute to the pathologically decreased permeability of glaucomatous TM. Modification of the peptide A $\beta 1-42$ by $\mathrm{LGE}_{2}$ promotes aggregation that may contribute to the development of Alzheimer's disease [37]. Nascent LG/ isoLG-protein adducts are highly reactive, and they can form cross-links with other proteins [38] as well as with DNA [39] or with small molecule amines such as glycine [38].

Consequently, nascent LG/isoLG-protein adducts may function as suicide inhibitors of cellular pathways, e.g., function of the proteasome [31]. LG/isoLG-modification may convert peptide/ protein ligands into reactive derivatives that become covalently bound with their receptors.

$\mathrm{LGE}_{2}$-protein adducts are formed in human platelets upon activation with exogenous arachidonic acid or thrombin, and formation of these adducts is inhibited by indomethacin, a prostaglandin $\mathrm{H}$ synthtase (PGHS) inhibitor, and is enhanced by an inhibitor of thromboxane synthase [40]. Thus, $\mathrm{LGE}_{2}$ can be formed via a PGHS-dependent pathway in whole cells, even in the presence of an enzyme that metabolizes $\mathrm{PGH}_{2}$, the precursor of $\mathrm{LGE}_{2} . \mathrm{LGE}_{2}$ can be generated either by ROS-mediated, nonenzymatic oxidation of lipids or COX-mediated arachidonic acid metabolism [41], while iso[4] $\mathrm{LGE}_{2}$ is produced exclusively via ROS-induced oxidation of arachidonic acid and its esters followed by rearrangements of endoperoxide intermediates [21,41]. Arachidonic acid also exacerbates ethanol-induced inflammatory responses in Kupffer cells [42]. These data encouraged us to hypothesize that the proinflammatory effects of arachidonic acid might be mediated, at least in part, via the formation of its metabolites, $\mathrm{LGE}_{2}$ or iso[4] $\mathrm{LGE}_{2}$, in response to ethanol exposure.

Previous reports demonstrate higher 4-HNE-protein adduct formation around the central veins of the liver in chronic ethanol-fed rats [3] and liver biopsies from patients with alcoholic liver injury [26]. We also detected comparatively higher ethanol-induced $\mathrm{LGE}_{2}$ and iso[4] $\mathrm{LGE}_{2}$ protein adduct accumulation around the central veins in some of the mouse livers, however, the majority of the sections showed no zone-specific adduct accumulation.

COX exists in two different isoforms, COX-1 and 2 [43]. COX -1 is constitutively expressed, while the inducible isoform COX-2 is over-expressed in the liver under various pathological conditions $[44,45]$ including chronic ethanol-induced liver injury [9,43]. Different arachidonic acid metabolites produced by $\mathrm{COX}-1$ and $\mathrm{COX}-2$, including thromboxane, prostaglandin $\mathrm{E}_{2}$ and prostacyclin, are already implicated in various inflammatory disease models [46]. However, the specific role of each COX isozyme on the production of $\gamma$-ketoaldehydes in vivo has not been investigated. We therefore dissected the role of ROS and COX in ethanolinduced overproduction of different reactive aldehyde-protein adducts. Neither COX-1 nor COX-2 deficiency affected the formation of $\mathrm{LGE}_{2}$ or iso[4] $\mathrm{LGE}_{2}$-protein adducts in mouse liver in response to 7 days of ethanol exposure, ruling out a direct role for COX in the early phases of ethanol-induced lipid peroxidation. Although expression of hepatic COX-2 increased following weeks of intra-gastric feeding of ethanol [9], we were unable to detect an increase in COX-2 protein in whole liver with ad libitum ethanol feeding for 11 days $(4 \% \mathrm{~d} 7)$ (data not shown). Moreover, ethanol-induced elevation in ALT and TG were similar in both wild type and COX-2 deficient mouse liver (data not shown), excluding the contribution of specific cyclooxygenase isozymes to early ethanol-induced steatosis and hepatic injury. These data suggest that ROS-mediated oxidation of arachidonic acid followed by nonenzymatic rearrangement of endoperoxide intermediates, rather than the activity of COX-1 or 2 , is more crucial for the formation of $\gamma$-ketoaldehyde-protein adducts in mouse liver following ethanol exposure. 
While our data demonstrate that ethanol-induced overproduction of $\mathrm{LGE}_{2}$ and iso[4] $\mathrm{LGE}_{2}$ is dependent on ROS, they do not identify the source of ROS necessary for ethanol-induced $\gamma$ ketoaldehyde overproduction. Accumulating data suggest that ethanol feeding induces ROS formation in the liver via a variety of cellular pathways, which include mitochondrial dysfunction [24], decreased anti-oxidants in mitochondria [47], up-regulation of CYP2E1 in hepatocytes [18] and NADPH oxidase in Kupffer cells [48]. CYP2E1, one of the major ethanol metabolizing enzymes in the liver, plays a key role in ethanol-induced ROS production [18, 23,49]. Ethanol metabolism by CYP2E1 also induces NF- $\kappa B$ activation [50] and promotes the formation of the mitochondrial permeability transition pore (MPTP) in response to ethanol feeding [24]. Inhibition of CYP2E1 by chlormethiazole or using CYP2E1-deficient mice attenuates ethanol-induced hepatic lipid peroxidation and steatosis in mouse liver [18]. Our data demonstrate that CYP2E1 induction starting at 11 days (4\% d7) onwards of ethanol feeding was accompanied by increased $\gamma$-ketoaldehyde-adduct formation and tissue injury markers, plasma ALT and hepatic TG. In the short-term model of ethanol feeding, CYP2E1 was induced only at $6 \%$ ethanol, concurrent with the increase in $\gamma$-ketoaldehyde-adducts. These data suggest that CYP2E1-induced ROS contributed, at least in part, to ethanol-induced adduct formation. In agreement with this hypothesis, CYP2E1-deficient mice exhibited ameliorated 4-HNE/iso[4] $\mathrm{LGE}_{2}$-protein adduct formation in response to ethanol feeding.

Induction of the pro-inflammatory cytokine, TNF- $\alpha$, plays a critical role in ethanol-induced liver damage [16,17]. Deficiency of TNFR1 attenuates ethanol-induced hepatic toxicity [16] and lipid peroxidation [51]. Ethanol feeding for 5 weeks induces TNF- $\alpha$ in mouse liver in a biphasic manner [22]. The early and transient induction of TNF- $\alpha$ occurs before the onset of ethanol-induced lipid peroxidation and liver injury, while the later induction of TNF- $\alpha$ is accompanied by oxidative stress and elevated tissue injury [22]. Elimination of TNF- $\alpha$ signaling, using TNFR1-deficient mice, blunted the production of $\mathrm{LGE}_{2}$ and iso[4] $\mathrm{LGE}_{2}-$ protein adducts in response to ethanol feeding, suggesting signaling via TNFR1 is pivotal for ethanol-induced lipid peroxidation. ROS produced by CYP2E1 sensitizes hepatocytes to TNF$\alpha$-mediated liver injury [52]. Moreover, deficiency of CYP2E1 prevents induction of TNF- $\alpha$ and formation of 4-HNE in response to acute ethanol feeding [53]. Taken together, these data suggest that TNF- $\alpha$ is a major contributor to ethanol-induced lipid peroxidation in the liver. Excessive ROS production, after chronic ethanol feeding also sensitizes the hepatocytes to TNF- $\alpha$-mediated toxicity [24], likely contributing to aggravated lipid peroxidation and tissue damage.

In summary, here we report that ethanol feeding induced the formation of novel $\gamma$ ketoaldehydes, i.e., LGs/isoLGs, in mouse liver which readily bind to proteins to form stable covalent adducts. TNFR1 and CYP2E1 are critical for iso[4]LGE 2 -protein adduct formation in mouse livers while arachidonic acid metabolizing enzymes, COX-1 or 2 do not contribute to the ethanol-induced formation of $\gamma$-ketoaldehyde-adducts. Similar to acetaldehyde or malondialdehyde adducts, these $\gamma$-ketoaldehyde adducts are likely to contribute to ethanolinduced liver injury inter alia by triggering pro-inflammatory responses and/or eliciting adduct specific immune reactions.

\section{Acknowledgments}

Grant support: This work was supported by NIH grants AA 013868 and AA 011975 to LE Nagy and GM 21249 and HL 53315 to Dr. Salomon.

\section{Abbreviations}

ALT, alanine aminotransferase activity

COX, cyclooxygenase 
PBS, phosphate buffered saline

ROS, reactive oxygen species

SEM, standard error of the mean

TNF- $\alpha$, tumor necrosis factor $\alpha$

$\mathrm{LGE}_{2}$, levuglandin $\mathrm{E}_{2}$

iso[4] $\mathrm{LGE}_{2}$, iso[4]levuglandin $\mathrm{E}_{2}$

4-HNE, 4-hydroxynonenal

MDA, malondialdehyde

FI, Fluorescence intensity

\section{References}

[1]. Nagata K, Suzuki H, Sakaguchi S. Common pathogenic mechanism in development progression of liver injury caused by non-alcoholic or alcoholic steatohepatitis. J Toxicol Sci 2007;32:453-468. [PubMed: 18198478]

[2]. Lumeng L, Crabb DW. Alcoholic liver disease. Curr Opin Gastroenterol 2000;16:208-218. [PubMed: 17023878]

[3]. Li CJ, Nanji AA, Siakotos AN, Lin RC. Acetaldehyde-modified and 4-hydroxynonenal-modified proteins in the livers of rats with alcoholic liver disease. Hepatology 1997;26:650-657. [PubMed: 9303495]

[4]. Tuma DJ. Role of malondialdehyde-acetaldehyde adducts in liver injury. Free Radic Biol Med 2002;32:303-308. [PubMed: 11841919]

[5]. Brame CJ, Boutaud O, Davies SS, Yang T, Oates JA, Roden D, Roberts LJ 2nd. Modification of proteins by isoketal-containing oxidized phospholipids. J Biol Chem 2004;279:13447-13451. [PubMed: 14715668]

[6]. Salomon RG, Subbanagounder G, O’Neil J, Kaur K, Smith MA, Hoff HF, Perry G, Monnier VM. Levuglandin E2-protein adducts in human plasma and vasculature. Chem Res Toxicol 1997;10:536-545. [PubMed: 9168251]

[7]. Davies SS, Talati M, Wang X, Mernaugh RL, Amarnath V, Fessel J, Meyrick BO, Sheller J, Roberts LJ 2nd. Localization of isoketal adducts in vivo using a single-chain antibody. Free Radic Biol Med 2004;36:1163-1174. [PubMed: 15082070]

[8]. Salomon RG, Batyreva E, Kaur K, Sprecher DL, Schreiber MJ, Crabb JW, Penn MS, DiCorletoe AM, Hazen SL, Podrez EA. Isolevuglandin-protein adducts in humans: products of free radicalinduced lipid oxidation through the isoprostane pathway. Biochim Biophys Acta 2000;1485:225235. [PubMed: 10832102]

[9]. Nanji AA, Miao L, Thomas P, Rahemtulla A, Khwaja S, Zhao S, Peters D, Tahan SR, Dannenberg AJ. Enhanced cyclooxygenase-2 gene expression in alcoholic liver disease in the rat. Gastroenterology 1997;112:943-951. [PubMed: 9041257]

[10]. Tipoe GL, Liong EC, Casey CA, Donohue TM Jr. Eagon PK, So H, Leung TM, Fogt F, Nanji AA. A voluntary oral ethanol-feeding rat model associated with necroinflammatory liver injury. Alcohol Clin Exp Res 2008;32:669-682. [PubMed: 18341647]

[11]. Salomon RG, Kaur K, Batyreva E. Isolevuglandin-protein adducts in oxidized low density lipoprotein and human plasma: a strong connection with cardiovascular disease. Trends Cardiovasc Med 2000;10:53-59. [PubMed: 11150730]

[12]. Boutaud O, Montine TJ, Chang L, Klein WL, Oates JA. PGH2-derived levuglandin adducts increase the neurotoxicity of amyloid beta1-42. J Neurochem 2006;96:917-923. [PubMed: 16412101]

[13]. Poliakov E, Brennan ML, Macpherson J, Zhang R, Sha W, Narine L, Salomon RG, Hazen SL. Isolevuglandins, a novel class of isoprostenoid derivatives, function as integrated sensors of oxidant stress and are generated by myeloperoxidase in vivo. FASEB J 2003;17:2209-2220. [PubMed: 14656983]

[14]. Yin M, Gabele E, Wheeler MD, Connor H, Bradford BU, Dikalova A, Rusyn I, Mason R, Thurman RG. Alcohol-induced free radicals in mice: direct toxicants or signaling molecules? Hepatology 2001;34:935-942. [PubMed: 11679964] 
[15]. Ding WX, Ni HM, DiFrancesca D, Stolz DB, Yin XM. Bid-dependent generation of oxygen radicals promotes death receptor activation-induced apoptosis in murine hepatocytes. Hepatology 2004;40:403-413. [PubMed: 15368445]

[16]. Yin M, Wheeler MD, Kono H, Bradford BU, Gallucci RM, Luster MI, Thurman RG. Essential role of tumor necrosis factor alpha in alcohol-induced liver injury in mice. Gastroenterology 1999;117:942-952. [PubMed: 10500078]

[17]. Iimuro Y, Gallucci RM, Luster MI, Kono H, Thurman RG. Antibodies to tumor necrosis factor alfa attenuate hepatic necrosis and inflammation caused by chronic exposure to ethanol in the rat. Hepatology 1997;26:1530-1537. [PubMed: 9397994]

[18]. Lu Y, Zhuge J, Wang X, Bai J, Cederbaum AI. Cytochrome P450 2E1 contributes to ethanol-induced fatty liver in mice. Hepatology 2008;47:1483-1494. [PubMed: 18393316]

[19]. Lee SS, Buters JT, Pineau T, Fernandez-Salguero P, Gonzalez FJ. Role of CYP2E1 in the hepatotoxicity of acetaminophen. J Biol Chem 1996;271:12063-12067. [PubMed: 8662637]

[20]. Gonzalez FJ, Kimura S. Understanding the role of xenobiotic-metabolism in chemical carcinogenesis using gene knockout mice. Mutation research 2001;477:79-87. [PubMed: 11376689]

[21]. Salomon RG, Sha W, Brame C, Kaur K, Subbanagounder G, O’Neil J, Hoff HF, Roberts LJ 2nd. Protein adducts of is[4]levuglandin E2, a product of the isoprostane pathway, in oxidized low density lipoprotein. J Biol Chem 1999;274:20271-20280. [PubMed: 10400646]

[22]. Roychowdhury S, McMullen MR, Pritchard MT, Hise AG, van Rooijen N, Medof ME, Stavitsky AB, Nagy LE. An early complement-dependent and TLR-4-independent phase in the pathogenesis of ethanol-induced liver injury in mice. Hepatology 2009;49:1326-1334. [PubMed: 19133650]

[23]. Lu Y, Cederbaum AI. CYP2E1 and oxidative liver injury by alcohol. Free Radic Biol Med 2008;44:723-738. [PubMed: 18078827]

[24]. Pastorino JG, Hoek JB. Ethanol potentiates tumor necrosis factor-alpha cytotoxicity in hepatoma cells and primary rat hepatocytes by promoting induction of the mitochondrial permeability transition. Hepatology 2000;31:1141-1152. [PubMed: 10796891]

[25]. Albano E. Oxidative mechanisms in the pathogenesis of alcoholic liver disease. Molecular aspects of medicine 2008;29:9-16. [PubMed: 18045675]

[26]. Niemela O. Distribution of ethanol-induced protein adducts in vivo: relationship to tissue injury. Free Radic Biol Med 2001;31:1533-1538. [PubMed: 11744326]

[27]. Brame CJ, Salomon RG, Morrow JD, Roberts LJ 2nd. Identification of extremely reactive gammaketoaldehydes (isolevuglandins) as products of the isoprostane pathway and characterization of their lysyl protein adducts. J Biol Chem 1999;274:13139-13146. [PubMed: 10224068]

[28]. Patel VB, Spencer CH, Young TA, Lively MO, Cunningham CC. Effects of 4-hydroxynonenal on mitochondrial 3-hydroxy-3-methylglutaryl (HMG-CoA) synthase. Free Radic Biol Med 2007;43:1499-1507. [PubMed: 17964421]

[29]. Salomon RG, Jirousek MR, Ghosh S, Sharma RB. Prostaglandin endoperoxides 21. Covalent binding of levuglandin E2 with proteins. Prostaglandins 1987;34:643-656. [PubMed: 3481092]

[30]. Davies SS, Amarnath V, Montine KS, Bernoud-Hubac N, Boutaud O, Montine TJ, Roberts LJ 2nd. Effects of reactive gamma-ketoaldehydes formed by the isoprostane pathway (isoketals) and cyclooxygenase pathway (levuglandins) on proteasome function. Faseb J 2002;16:715-717. [PubMed: 11978738]

[31]. Govindarajan B, Laird J, Sherman R, Salomon RG, Bhattacharya SK. Neuroprotection in glaucoma using calpain-1 inhibitors: regional differences in calpain-1 activity in the trabecular meshwork, optic nerve and implications for therapeutics. CNS \& neurological disorders drug targets 2008;7:295-304. [PubMed: 18673213]

[32]. Zagol-Ikapitte I, Masterson TS, Amarnath V, Montine TJ, Andreasson KI, Boutaud O, Oates JA. Prostaglandin H(2)-derived adducts of proteins correlate with Alzheimer's disease severity. J Neurochem 2005;94:1140-1145. [PubMed: 15992375]

[33]. Fukuda K, Davies SS, Nakajima T, Ong BH, Kupershmidt S, Fessel J, Amarnath V, Anderson ME, Boyden PA, Viswanathan PC, Roberts LJ 2nd, Balser JR. Oxidative mediated lipid peroxidation recapitulates proarrhythmic effects on cardiac sodium channels. Circulation research 2005;97:1262-1269. [PubMed: 16284182] 
[34]. Boyden PA, Davies SS, Viswanathan PC, Amarnath V, Balser JR, Roberts LJ 2nd. Potential role of isoketals formed via the isoprostane pathway of lipid peroxidation in ischemic arrhythmias. Journal of cardiovascular pharmacology 2007;50:480-486. [PubMed: 18030056]

[35]. Govindarajan B, Laird J, Salomon RG, Bhattacharya SK. Isolevuglandin-modified proteins, including elevated levels of inactive calpain-1, accumulate in glaucomatous trabecular meshwork. Biochemistry 2008;47:817-825. [PubMed: 18085799]

[36]. Murthi KK, Salomon RG, Sternlicht H. Levuglandin E2 inhibits mitosis and microtubule assembly. Prostaglandins 1990;39:611-622. [PubMed: 2115185]

[37]. Boutaud O, Ou JJ, Chaurand P, Caprioli RM, Montine TJ, Oates JA. Prostaglandin H2 (PGH2) accelerates formation of amyloid beta1-42 oligomers. J Neurochem 2002;82:1003-1006. [PubMed: 12358806]

[38]. Iyer RS, Ghosh S, Salomon RG. Levuglandin E2 crosslinks proteins. Prostaglandins 1989;37:471480. [PubMed: 2762557]

[39]. Murthi KK, Friedman LR, Oleinick NL, Salomon RG. Formation of DNA-protein cross-links in mammalian cells by levuglandin E2. Biochemistry 1993;32:4090-4097. [PubMed: 8471616]

[40]. Boutaud O, Li J, Zagol I, Shipp EA, Davies SS, Roberts LJ 2nd, Oates JA. Levuglandinyl adducts of proteins are formed via a prostaglandin $\mathrm{H} 2$ synthase-dependent pathway after platelet activation. J Biol Chem 2003;278:16926-16928. [PubMed: 12637576]

[41]. Salomon RG. Distinguishing levuglandins produced through the cyclooxygenase and isoprostane pathways. Chemistry and physics of lipids 2005;134:1-20. [PubMed: 15752459]

[42]. Cubero FJ, Nieto N. Ethanol and arachidonic acid synergize to activate Kupffer cells and modulate the fibrogenic response via tumor necrosis factor alpha, reduced glutathione, and transforming growth factor beta-dependent mechanisms. Hepatology 2008;48:2027-2039. [PubMed: 19003881]

[43]. Holt AP, Adams DH. Complex roles of cyclo-oxygenase 2 in hepatitis. Gut 2007;56:903-904. [PubMed: 17566025]

[44]. Sung YK, Hwang SY, Kim JO, Bae HI, Kim JC, Kim MK. The correlation between cyclooxygenase-2 expression and hepatocellular carcinogenesis. Molecules and cells 2004;17:3538. [PubMed: 15055524]

[45]. Kondo M, Yamamoto H, Nagano H, Okami J, Ito Y, Shimizu J, Eguchi H, Miyamoto A, Dono K, Umeshita K, Matsuura N, Wakasa K, Nakamori S, Sakon M, Monden M. Increased expression of COX-2 in nontumor liver tissue is associated with shorter disease-free survival in patients with hepatocellular carcinoma. Clin Cancer Res 1999;5:4005-4012. [PubMed: 10632332]

[46]. Funk CD. Prostaglandins and leukotrienes: advances in eicosanoid biology. Science (New York, N.Y 2001;294:1871-1875.

[47]. Fernandez-Checa JC, Kaplowitz N. Hepatic mitochondrial glutathione: transport and role in disease and toxicity. Toxicology and applied pharmacology 2005;204:263-273. [PubMed: 15845418]

[48]. Thakur V, Pritchard MT, McMullen MR, Wang Q, Nagy LE. Chronic ethanol feeding increases activation of NADPH oxidase by lipopolysaccharide in rat Kupffer cells: role of increased reactive oxygen in LPS-stimulated ERK1/2 activation and TNF-alpha production. Journal of leukocyte biology 2006;79:1348-1356. [PubMed: 16554353]

[49]. Sampey BP, Korourian S, Ronis MJ, Badger TM, Petersen DR. Immunohistochemical characterization of hepatic malondialdehyde and 4-hydroxynonenal modified proteins during early stages of ethanol-induced liver injury. Alcohol Clin Exp Res 2003;27:1015-1022. [PubMed: 12824824]

[50]. Kim WH, Hong F, Jaruga B, Hu Z, Fan S, Liang TJ, Gao B. Additive activation of hepatic NFkappaB by ethanol and hepatitis B protein X (HBX) or HCV core protein: involvement of TNFalpha receptor 1-independent and -dependent mechanisms. Faseb J 2001;15:2551-2553. [PubMed: 11641261]

[51]. Isayama F, Froh M, Yin M, Conzelmann LO, Milton RJ, McKim SE, Wheeler MD. TNF alphainduced Ras activation due to ethanol promotes hepatocyte proliferation independently of liver injury in the mouse. Hepatology 2004;39:721-731. [PubMed: 14999690]

[52]. Wu D, Cederbaum A. Cytochrome P4502E1 sensitizes to tumor necrosis factor alpha-induced liver injury through activation of mitogen-activated protein kinases in mice. Hepatology 2008;47:10051017. [PubMed: 18095305] 
[53]. Wang X, Lu Y, Cederbaum AI. Induction of cytochrome P450 2E1 increases hepatotoxicity caused by Fas agonistic Jo2 antibody in mice. Hepatology 2005;42:400-410. [PubMed: 16025513] 
A

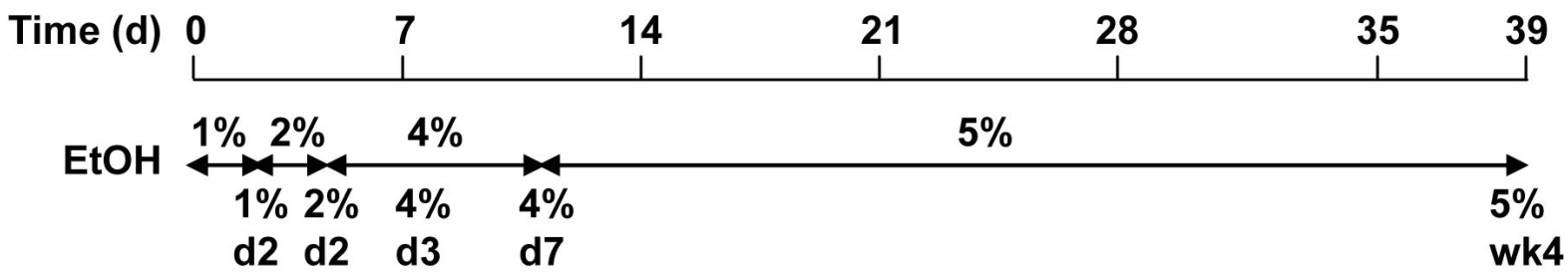
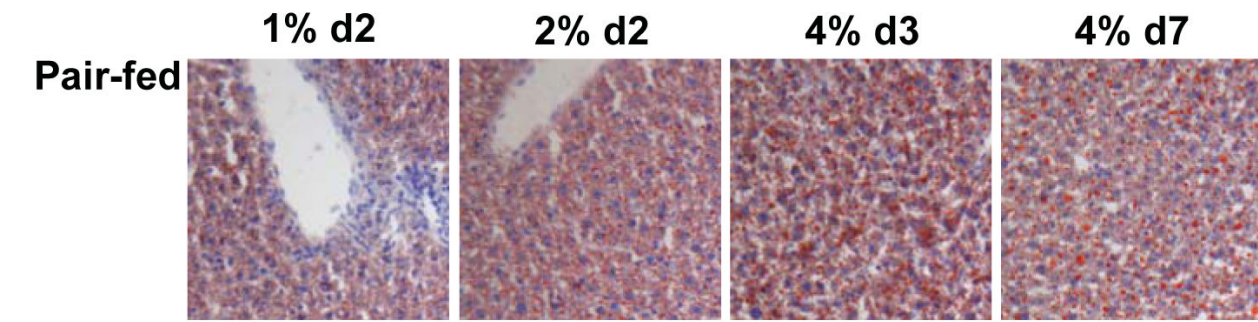

\section{$5 \%$ wk4}

EtOH-fed


B
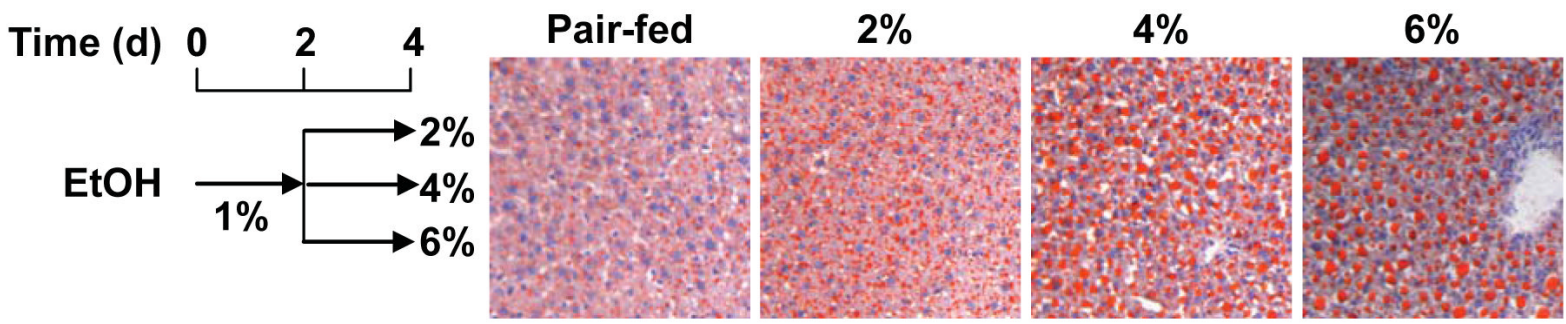

Figure 1.

Accumulation of neutral lipids in the liver of C57BL/6 mice after chronic or short-term ethanol feeding. Oil Red O staining was visualized in OCT embedded liver sections. A) Mice were allowed free access to diets containing increasing concentrations of ethanol or pair-fed control diets for 2 to 39 days, as indicated in the scheme. B) Mice were allowed free access to $1 \%$ ethanol diet for 2 days followed by increasing concentrations of ethanol-containing diets (2, 4 or $6 \%$ ) for 2 days, as indicated in the scheme. Control animals were pair-fed a diet which isocalorically substituted maltose dextrins for ethanol. Images were acquired using a10X objective. Figures are representative of at least 3 mice in each experimental group. 
A

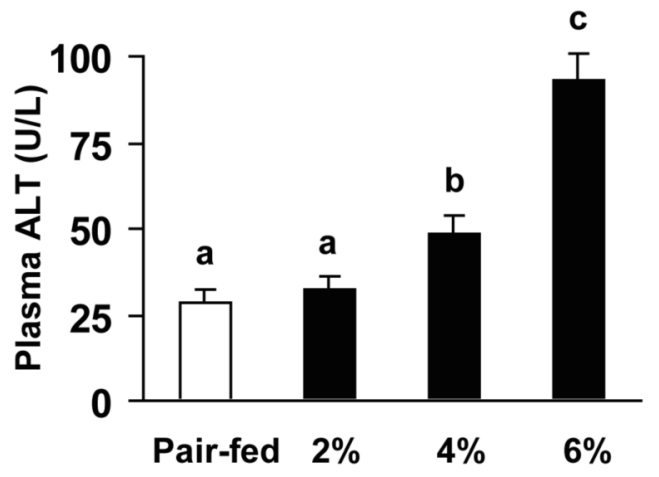

B

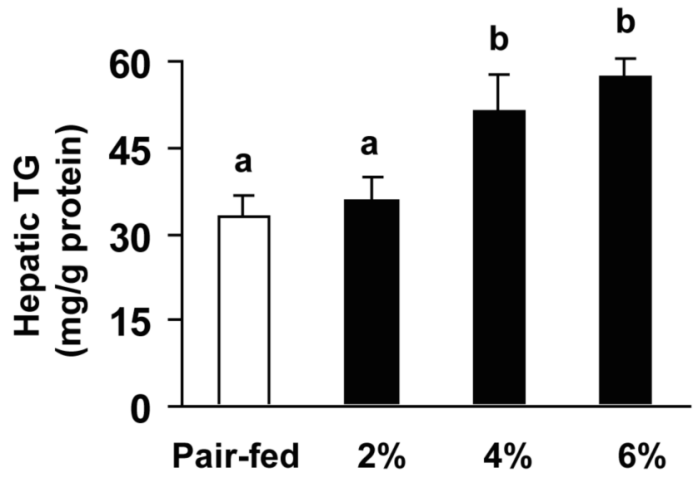

Figure 2.

Plasma ALT activity and hepatic triglyceride content measured in response to short-term ethanol feeding. Mice were allowed free access to a $1 \%$ ethanol diet for 2 days followed by diets containing increasing concentrations of ethanol (2, 4 or $6 \%)$ for 2 days or pair-fed control diets. A) Plasma ALT activity and B) hepatic triglyceride content were measured using an enzymatic assay. Values represent means \pm SEM, $n=4$. Groups with different alphabetical superscripts differ significantly $(\mathrm{p}<0.05)$. 
A



B



Figure 3.

CYP2E1 expression elevated in mouse livers after chronic ethanol feeding. (A) Mice were allowed free access to diets containing increasing concentrations of ethanol or pair-fed control diets for 2 to 39 days or (B) subjected to the short-term ethanol feeding for 4 days. Homogenates were prepared from livers of ethanol- and pair-fed mice and the expression of CYP2E1 assessed by Western blot analysis. Values represent means \pm SEM, $n=4$. For $(A) * p<0.05$ compared to pair-fed. For (B) groups with different alphabetical superscripts differ significantly $(\mathrm{p}<0.05)$. 
A
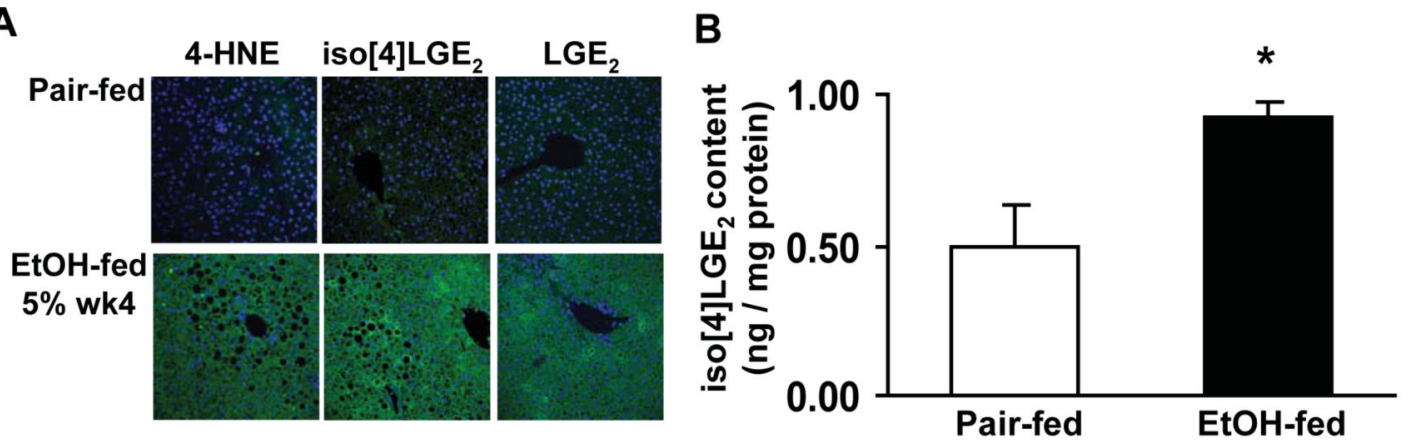

Figure 4.

Increased 4-HNE, iso[4] $\mathrm{LGE}_{2}$ or $\mathrm{LGE}_{2}$-protein adducts in mouse liver after chronic ethanol exposure. Mice were allowed free access to diets containing increasing concentrations of ethanol or pair-fed control diets for 2 to 39 days (5\% wk 4). A) Paraffin-embedded livers were de-paraffinized followed by immuno-detection of respective aldehyde-protein adducts using immunofluorescence. The blue fluorescence signal represents DAPI-stained nuclei while the green signal represents iso[4] $\mathrm{LGE}_{2} / \mathrm{LGE}_{2}$ or 4 -HNE-protein adducts. All images were acquired using a $40 \mathrm{X}$ objective. Figures are representative of 2-4 images per liver and at least 3 mice per experimental condition. B) Quantity of iso[4] $\mathrm{LGE}_{2}$-protein adduct was measured by ELISA in liver homogenates. Values represent means \pm SEM, $n=3$ to 5 , $* \mathrm{p}<0.05$ compared to pair-fed. 
A

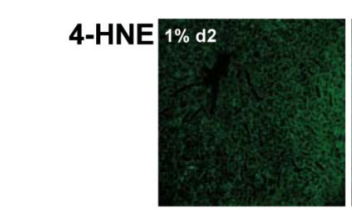

iso[4] $\operatorname{LGE}_{2} 1 \% \mathrm{~d} 2$

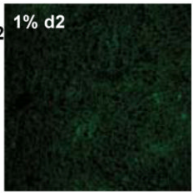

$\operatorname{LGE}_{2} 1 \% \mathrm{~d} 2$

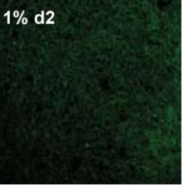

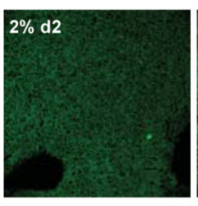
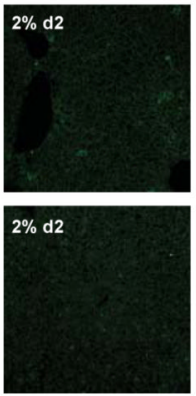
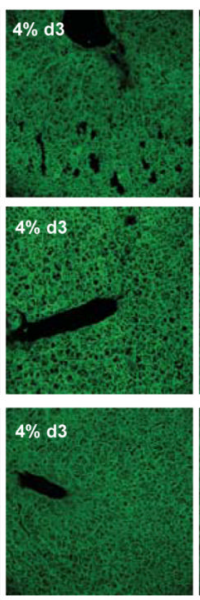
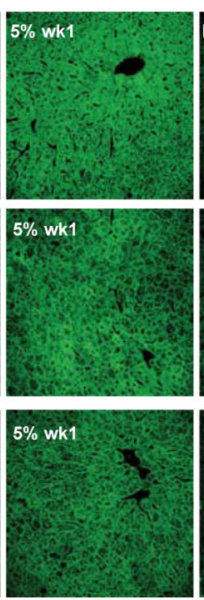

B

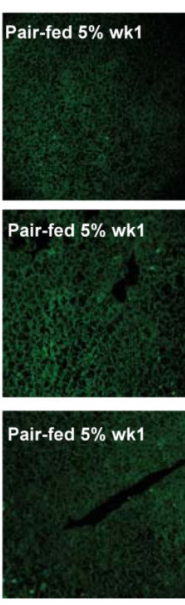

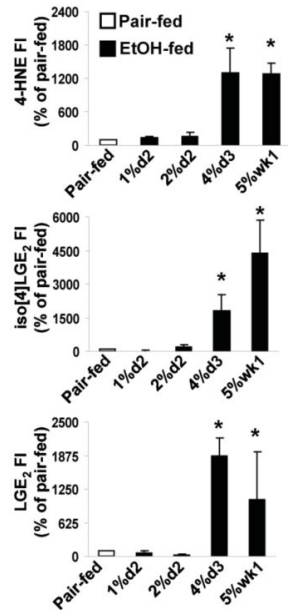

Figure 5.

Time-dependent increase of 4-HNE, iso[4] $\mathrm{LGE}_{2}$ or $\mathrm{LGE}_{2}$-protein adducts in mouse liver during chronic ethanol exposure. Mice were allowed free access to diets containing increasing concentrations of ethanol or pair-fed control diets for 2 to 39 days (5\% wk 4). (A) Paraffinembedded livers were de-paraffinized followed by immuno-detection of 4-HNE, iso[4] $\mathrm{LGE}_{2}$ or $\mathrm{LGE}_{2}$-protein adducts using immunofluorescence. All images were acquired using a $40 \mathrm{X}$ objective. Figures are representative of 2-4 images per liver and 3 mice per experimental condition. (B) Fluorescence intensity of 4-HNE, iso[4] $\mathrm{LGE}_{2}$ or $\mathrm{LGE}_{2}$-protein adducts was semi-quantified using ImagePro software. Values represent mean $\pm \mathrm{SEM}, \mathrm{n}=3$ to 5 , ${ }^{*} \mathrm{p}<0.05$ compared to pair-fed. FI: Fluorescence intensity. 
A

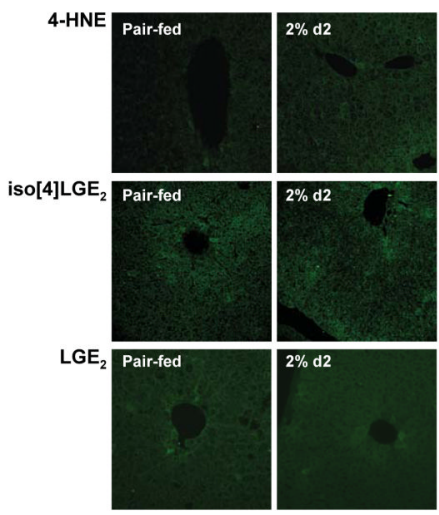

B
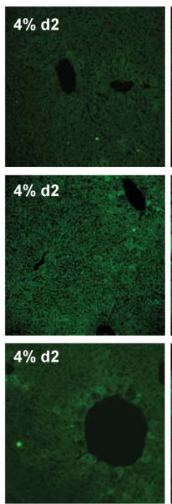
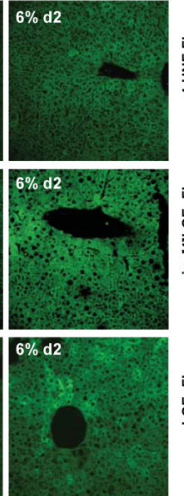

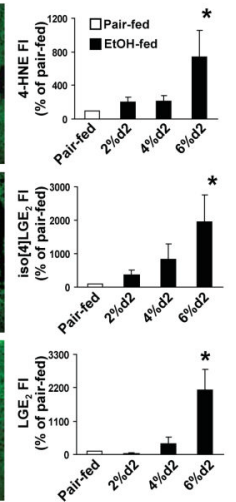

Figure 6.

Ethanol-induced increases in 4-HNE, iso[4] $\mathrm{LGE}_{2}$ or $\mathrm{LGE}_{2}$-protein adducts in mouse liver was dose-dependent. Mice were allowed free access to $1 \%$ ethanol diet followed by diets containing increasing concentrations of ethanol $(2,4$ or $6 \%)$ for 2 days or pair-fed control diets. (A)

Paraffin-embedded livers were de-paraffinized followed by immuno-detection of 4-HNE, iso [4] $\mathrm{LGE}_{2}$ or $\mathrm{LGE}_{2}$-protein adducts using immunofluorescence. All images were acquired using a $40 \mathrm{X}$ objective. Figures are representative of 2-4 images per liver and 3 mice per experimental condition. (B) Fluorescence intensity of 4-HNE, iso[4] $\mathrm{LGE}_{2}$ or $\mathrm{LGE}_{2}$-protein adducts was semi-quantified using ImagePro software. Values represent mean \pm SEM, $n=3$ to 5 , ${ }^{*} \mathrm{p}<0.05$ compared to pair-fed. FI: Fluorescence intensity. 
A

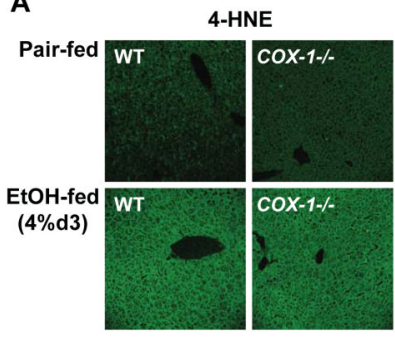

B

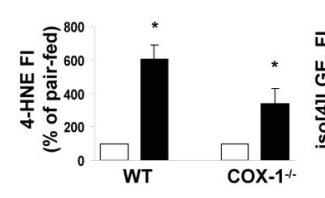

iso[4]LGE
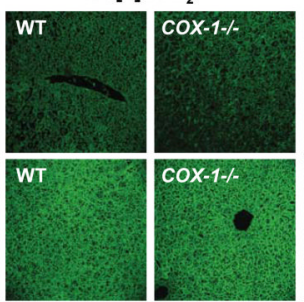

$\operatorname{cox}-1 \%$

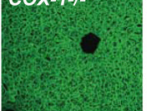

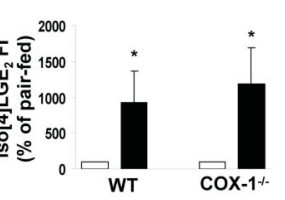

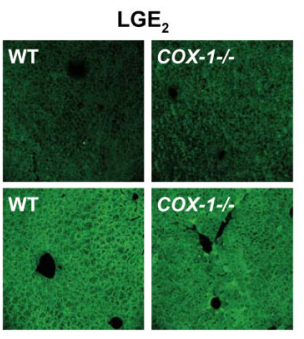

QPair-fed

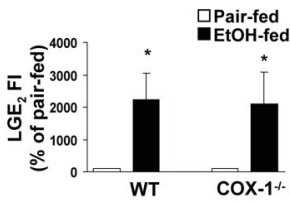

Figure 7.

Ethanol-induced $\gamma$-ketoaldehyde-adduct formation in wild type and COX-1-deficient mouse liver. Wild type and $\mathrm{COX}-1^{-/-}$mice were allowed free access to diets containing increasing concentrations of ethanol (4\% d3) or pair-fed control diets for 7 days. (A) Paraffin-embedded livers were de-paraffinized followed by immuno-detection of 4-HNE, iso[4] $\mathrm{LGE}_{2}$ and $\mathrm{LGE}_{2}$ protein adducts using immunofluorescence. All images were acquired using a 40X objective. Figures are representative of 2-3 images per liver and 4-6 mice per experimental condition. (B) Fluorescence intensity of 4-HNE, iso[4]LGE 2 or $\mathrm{LGE}_{2}$-protein adducts was semiquantified using ImagePro software. Values represent mean \pm SEM, $n=3$ to 5 , * $p<0.05$ compared to pair-fed. FI: Fluorescence intensity. 
A
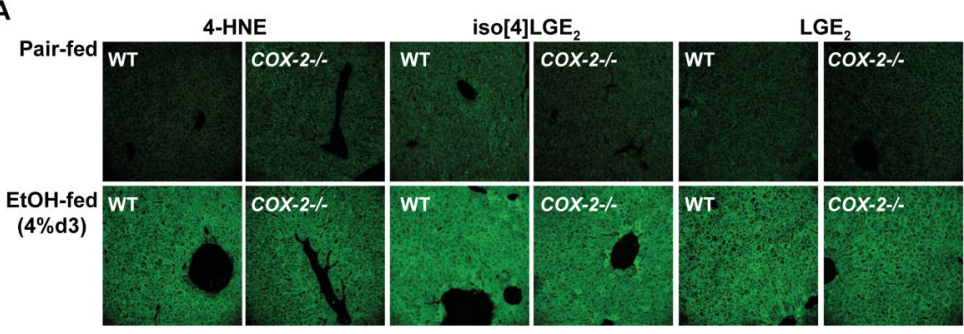

B

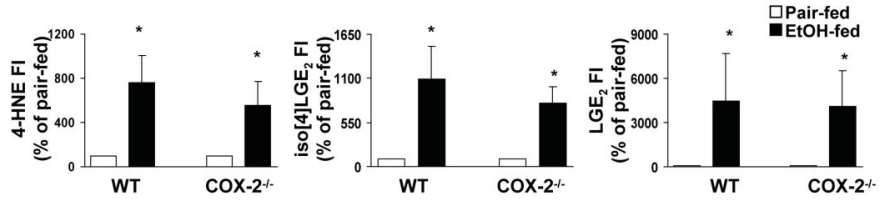

Figure 8.

Ethanol-induced $\gamma$-ketoaldehyde-adduct formation in wild type and COX-2-deficient mouse liver. Wild type and COX $-2^{-1-}$ mice were allowed free access to diets containing increasing concentrations of ethanol $(4 \% \mathrm{~d} 3)$ or pair-fed control diets for 7 days. (A) Paraffin-embedded livers were de-paraffinized followed by immuno-detection of 4-HNE, iso[4]LGE 2 and $\mathrm{LGE}_{2}$ protein adducts using immunofluorescence. All images were acquired using a 40X objective. Figures are representative of 2-3 images per liver and 4-6 mice per experimental condition. (B) Fluorescence intensity of 4-HNE, iso[4]LGE 2 or $\mathrm{LGE}_{2}$-protein adducts was semiquantified using ImagePro software. Values represent mean \pm SEM, $n=3$ to 5 , ${ }^{*} \mathrm{p}<0.05$ compared to pair-fed. FI: Fluorescence intensity. 
A

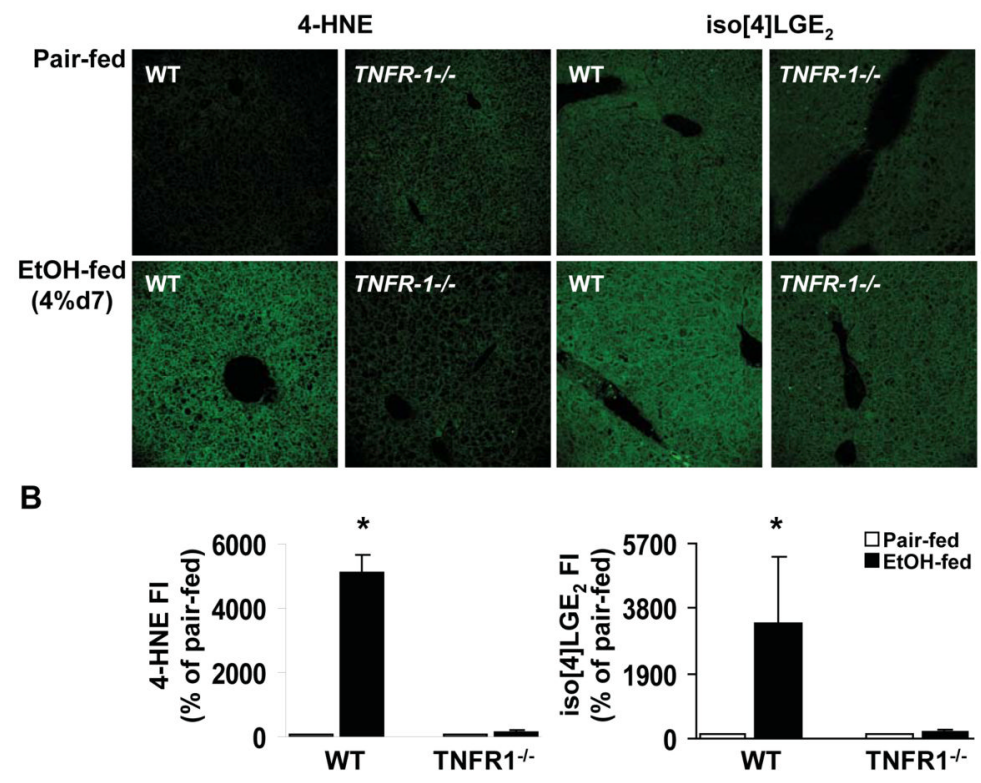

Figure 9.

TNFR1 deficiency prevented ethanol-induced $\gamma$-ketoaldehyde-adduct formation. Wild type and TNFR $1^{-1-}$ mice were allowed free access to diets containing increasing concentrations of ethanol (4\% d7) or pair-fed control diets for 11 days. (A) Paraffin-embedded livers were deparaffinized followed by immuno-detection of 4-HNE and iso[4]LGE 2 -protein adducts using immunofluorescence. All images were acquired using a 40X objective. Figures are representative of 2-3 images per liver and 3 mice per experimental condition. (B) Fluorescence intensity of 4-HNE, iso[4] $\mathrm{LGE}_{2}$ or $\mathrm{LGE}_{2}$-protein adducts was semi-quantified using ImagePro software. Values represent mean \pm SEM, $n=3$ to $5,{ }^{*} \mathrm{p}<0.05$ compared to pair-fed. FI: Fluorescence intensity. 
A

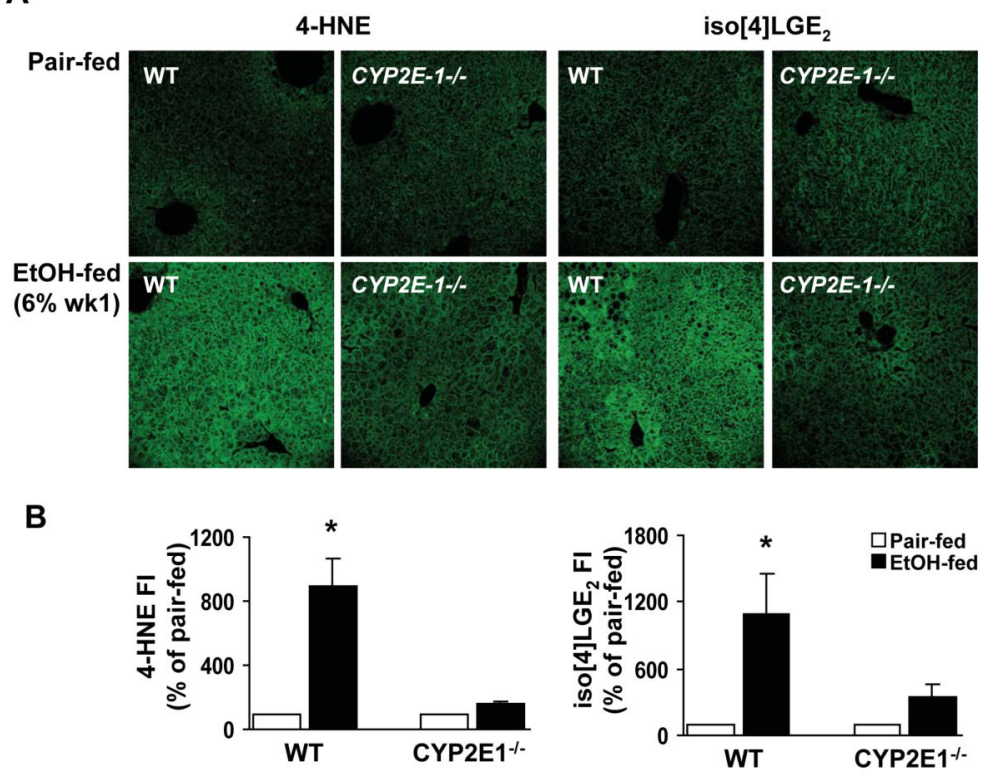

Figure 10.

CYP2E1 deficiency blunted ethanol-induced $\gamma$-ketoaldehyde-adduct formation in mouse liver. Wild type and CYP2E1 $1^{-/-}$mice were allowed free access to diets containing increasing concentrations of ethanol ( $6 \%$ wk1) or pair-fed control diets for 4 weeks. (A) Paraffinembedded liver sections were de-paraffinized followed by immuno-detection of 4-HNE and iso[4]LGE 2 -protein adducts using immunofluorescence. All images were acquired using a 40X objective. Figures are representative of 2-3 images per liver and 3 mice per experimental condition. (B) Fluorescence intensity of 4-HNE, iso[4] $\mathrm{LGE}_{2}$ or $\mathrm{LGE}_{2}$-protein adducts was semi-quantified using ImagePro software. Values represent mean \pm SEM, $n=3$ to 5 , $* \mathrm{p}<0.05$ compared to pair-fed. FI: Fluorescence intensity. 